\title{
Yb-Decorated Carbon Nanotubes As a Potential Capacity Hydrogen Storage Medium*
}

\author{
Hong-Wen Lei, Hong Zhang, Wei-Dong Wu \\ Science and Technology on Plasma physics Laboratory, Research Center of Laser Fusion, China Academy of Engineering Physics, \\ Mianyang 621900, China \\ Institution of Atomic and Molecular Physics, Sichuan University, Chengdu 610065, China \\ College of Physical Science and Technology, Sichuan University, Chengdu 610065, China \\ Email: wuweidongding@163.com
}

Received 2012

\begin{abstract}
We report a first-principles study, which demonstrates that a single $\mathrm{Yb}$ atom coated on a single-walled nanotube (SWNT), B atom doped CNT and N atom doped CNT binds up to six hydrogen molecules. At high Yb coverage we show that a SWNT can strongly adsorb up to $3.18 \mathrm{wt} \%$ hydrogen. Yb-4f electrons have no contribution on the adsorption of hydrogen molecules in $\mathrm{Yb}$ doped CNT. The charge analysis results show that $4 \mathrm{f}$ electrons remain in $\mathrm{Yb}$. These results promote our fundamental understanding of dissociative adsorption of hydrogen in RE atom doped carbon nanostructures.
\end{abstract}

Keywords: Hydrogen Adsorption; Carbon Nanotubes; Density of States

\section{Introduction}

As one of the most abundant elements in the universe, hydrogen is receiving increasing attention as an friendly and clean energy for environment [1]. However, a wealth of fundamental and technical challenges on hydrogen transport and storage, such as high gravimetric and volumetric density, safety and low cost must be overcome before hydrogen fuel economy realized. The Department of Energy (DOE) of the US targets for the ideal hydrogen storage materials with the gravimetric storage capacity of hydrogen should reach $9 \mathrm{wt} \%$ by 2015[2]. Traditional methods to store hydrogen include using compressed gaseousor liquid $\mathrm{H}_{2}$, which demands high pressure and/or low temperature, or using solids that adsorb $\mathrm{H}_{2}$. Simultaneously, this approach is too expensive. In this cause, to achieve economic feasibility, hydrogen storage materials with high volumetric and gravimetric densities must be developed [3]. Suggestions for hydrogen adsorption in doped carbon nanotubes (CNTs) have been made because of the possibility of reversibility, fast kinetics, and high capacity (large surface area) [4-7]. However, it has been found that hydrogen on pure CNT currently falls short of the DOE targets. This is attributed to the weak interaction between hydrogen molecules and the carbon materials by physisorption [8,9]. More recent theoretical studies have

\footnotetext{
* This work was supported by Ministry of National Science and Technology Major Instrumentation Special (Grant No. 2011YQ130018)
}

been devoted tofinding and designing materials which enhance the interactions to the desirable binding energy of $0.2-0.6 \mathrm{eV}[10-16]$. K. Hirano et al's study suggest that 15 rare earth elements reveal characteristics of the capacity of hydrogen absorption. It is found that RE such as Eu prefers to adsorb at the hollow site of the hexagonal ring on the outer surface of the CNT. One of the most important advantages of RE (such as Eu) doping on CNT is that the electronic characteristics originating from the unpaired $4 \mathrm{f}$ electrons could serve as electron donors and thus increase $\mathrm{E}_{\mathrm{ad}}$ for $\mathrm{H}_{2}$ on CNT[17]. When $\mathrm{H}_{2}$ molecules are attach on $\mathrm{RE}$ atoms, electron transfers from $\mathrm{H}_{2}$ to Eu, filling an acceptor-like state. To our best knowledge, Ytterbium $(\mathrm{Yb})$, a member of the rare earth group metals with a filled $\mathrm{f}$ shell and a divalent electronic character, had not been studied for hydrogen adsorption when it attached to $(8,0)$ SWCNT. As the electron configuration of $\mathrm{Yb}$ is $[\mathrm{Xe}] 4 \mathrm{f}^{7} 6 \mathrm{~s}^{2}$, there are a large number of filled $4 \mathrm{f}$ orbital, and thus more $\mathrm{H}_{2}$ molecules could be adsorbed. In particular, we focus on the role of transferred charges between $\mathrm{Yb}$ and SWCNT on the affinity of $\mathrm{H}_{2}$. To achieve our goal, we conduct a systematic search for high-capacity hydrogen storage media consisting of indvidual $\mathrm{Yb}$ atoms decorated on CNT, B-CNT, N-CNT. Our results show that the hydrogen storage ability of SWCNT can be enhanced by doping $\mathrm{Yb}$ atoms and $\mathrm{Yb}-4 \mathrm{f}$ electrons have no contribution on the hydrogen adsorption but $\mathrm{Yb}-5 \mathrm{~d}$. 


\section{Computation Details}

Density functional theory (DFT) methods, implemented in the DMol3 package $[18,19]$, are used to study the systems which have been widely utilized for carbon nanotubles doped with lanthanide series metal $[17,20]$.Double Numerical plus polarization (DNP) atomic orbits were taken as basis sets[21]. Due to the crucial role that spin plays in this system, all our calculations have been performed in a spin unrestricted framework. All structural optimizations were obtained with symmetry constraints by using a convergence tolerance of energy of $1.0 \times 10^{-5}$ hartree, a maximum force is 0.002 hartree $/ \AA$ and a maximum displacement of 0.005 $\AA$. The orbital cut off was set to be global with a value of $5.0 \AA$, and smearing was $0.005 \mathrm{Ha}(1 \mathrm{Ha}=27.2114 \mathrm{eV})$. In the self-consistent-field calculations, the electronic-density convergence was set to $1.0 \times 10^{-6} \mathrm{e} / \AA^{3}$. In the present calculation, a hexagonal supercell was adopted, whose size was $25 \times 25 \times \mathrm{c} \AA^{3}$ with the length of $\mathrm{c}$ in the axial of $\mathrm{z}$ direction being two times of the periodicity of the $(8,0)$ nanotube. Supercell calculations were employed throughout where the carbon atoms on adjacent nanotubes are separated by over $10 \AA$. and the interaction between neighboring images could be neglected. The Brillouin zone of the supercell was sampled by $1 \times 1 \times 6 \mathrm{k}$-points within the Monkhorst-Pack scheme[22]. For comparison, the identical simulation parameters were employed in all simulations. Because the interaction between $\mathrm{H}_{2}$ and $\mathrm{Yb}$ usually renders significantly smaller or even repulsive interactions using GGA, however, the local density approximation (LDA) generally overestimates the $\mathrm{H} 2$ binding strength. So both LDA and GGA are described the binding energy of $\mathrm{H}_{2}$ dispersed CNT B-CNT, N-CNT, respectively [17, 23-25].

\section{Results and Discussion}

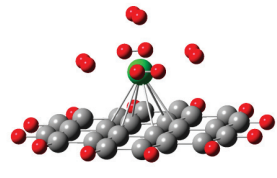

(a)

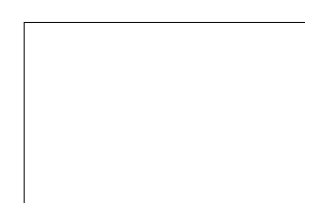

(b)

Figure 1. Coronene $\left(\mathrm{C}_{24} \mathrm{H}_{12}\right)$ planar sheet(a) and the hydrogen binding energy(b).Red, gray, green spheres represent hydrogen atoms, carbon atoms and $\mathrm{Yb}$ atoms, respectively

Coronene-like $\left(\mathrm{C}_{24} \mathrm{H}_{12}\right)$ planar sheet used as cluster-modeled carbon and hydrogen atoms. It is well know that carbon nanotubes curled from grapheme. One $\mathrm{Yb}$ atom doped $\mathrm{C}_{24} \mathrm{H}_{12}$ can attach five hydrogen molecules and average distance between $\mathrm{Yb}$ atom and the center of hydrogen molecules is $2.24 \AA$. The purpose of the hydrogen atoms is to passivate the dangling bonds of the polycyclic $\mathrm{sp}^{2}$ hybridized carbon structure. Binding energy and optimized structure are shown in Fig.1. To search for hydrogen-storage nanostructures consisting of combination of carbon nanotubes and $\mathrm{Yb}$, we consider a pristine $(8,0) \mathrm{CNT}$ and the case of boron substitutional doping, nitrogen substitutional doping CNT to examine the local structure of the $\mathrm{Yb}$ attachment. A single $\mathrm{Yb}$ atom is attached to each of the above three structures. We first evaluated the binding energy of a $\mathrm{Yb}$ atom (persupercell) to the pristine $(8,0) \mathrm{CNT}$. The $\mathrm{Yb}$ atom favors to locate at the hollow site of the hexagonal ring on the outer surface, which is consistent with other RE atoms [17]. The binding energy of a single $\mathrm{Yb}$ atom at hexagonal sites is defined as $\mathrm{E}_{\mathrm{B}}\left(\mathrm{Y}_{\mathrm{b}}\right)=\mathrm{E}(\mathrm{CNT})+\mathrm{E}(\mathrm{Ti})-\mathrm{E}(\mathrm{CNT}+\mathrm{Ti})$. The calculated binding energy of the $\mathrm{Yb}$ atom to the $(8,0) \mathrm{CNT}$ is $1.74 \mathrm{eV}$ and the $\mathrm{Yb}-\mathrm{C}$ bonds exist with bond

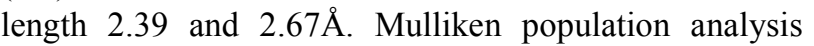
indicates that 0.45 e electrons are transferred from the $\mathrm{Yb}$ atom to $\mathrm{CNT}$, resulting in partially cationic $\mathrm{Yb}$ atom. When the first hydrogen molecule is adsorbed on the $\mathrm{Yb} / \mathrm{CNT}, \mathrm{H}-\mathrm{H}$ bond lengthn is $0.81 \AA$. Our calculations show that each $\mathrm{Yb}$ atom can hold up to six $\mathrm{H}_{2}$ molecules are attached on the $\mathrm{Yb} / \mathrm{CNT}$ both LDA and GGA. The resulting system, which is shown in Fig. 2, is denoted by $\mathrm{CNT} / \mathrm{Yb} /\left(\mathrm{H}_{2}\right)_{6}$. The final configuration is very symmetric, and all the hydrogen molecules benifit equally from the bonding with the $\mathrm{Yb}$ atom. The average binding energy per $\mathrm{H}_{2}$ is about $0.46 \mathrm{eV}$ (LDA), i.e., slightly smaller than that obtained for the first adsorption. We have also calculated the binding energy of $\mathrm{H}_{2}$ molecules on $\mathrm{Yb}$ in these three structures as a function of the number of hydrogen molecules adsorbed. The binding energy of $\mathrm{H}_{2}$ for an isolated $\mathrm{Yb}$ atom decorated on a pristine $(8,0) \mathrm{CNT}$, a nitrogen-dopant, a boron-dopant are shown in table 1 . The distance between $\mathrm{Yb}$ and the center of $\mathrm{H}_{2}$ and $\mathrm{H}-\mathrm{H}$ bond length on average are 2.64 and $0.76 \AA$ for $\mathrm{CNT} / \mathrm{Yb} /\left(\mathrm{H}_{2}\right)_{6}$. (The bond length of isolated $\mathrm{H}_{2}$ is calculated to be about $0.75 \AA$ with GGA). Since $\mathrm{H}_{2}$ physisorption on CNT is not reproduced at all in GGA [26,27], this observation implies that $\mathrm{H}_{2}$ adsorption on $\mathrm{Yb}$ is not in the physisorption regime. The binding energy of hydrogen molecules for LDA is excess the twice for GGA.

Figure 4 shows the fully optimized structure for a maximum hydrogen-storage capacity in $(8,0)$ CNT corresponding to $3.18 \mathrm{wt} \%$. We also computed the hydrogen adsorption of B-CNT and N-CNT, the results indicate that six $\mathrm{H}_{2}$ per $\mathrm{Yb}$ atom can be adsorbed onto B-CNT and N-CNT system where the molecular formula may be expressed as $\left(\mathrm{C}_{60} \mathrm{~N}_{4} \cdot 4 \mathrm{Yb} \cdot 24 \mathrm{H}_{2}\right)_{\mathrm{n}}$ and $\left(\mathrm{C}_{60} \mathrm{~B}_{4} \cdot 4 \mathrm{Yb} \cdot 24 \mathrm{H}_{2}\right)_{\mathrm{n}}$ ( $\mathrm{n}$ is an integer). $\mathrm{Eu}_{3} / \mathrm{SWCNT}$ can 
Table 1. Calculated binding energy of $\mathrm{eV} / \mathrm{H}_{2}$ for an $\mathrm{Yb}$ atom decorated on a pristine $(8,0) \mathrm{CNT}$ and on a N-CNT, B-CNT, respectively, as a function of the number of adsorbed $\mathrm{H}_{2}$ molecules.

Functional $\quad 1 \mathrm{H}_{2} \quad 2 \mathrm{H}_{2} \quad 3 \mathrm{H}_{2} \quad 4 \mathrm{H}_{2} \quad 5 \mathrm{H}_{2} \quad 6 \mathrm{H}_{2} \quad$ average $\mathrm{E}_{\mathrm{b}}$

\begin{tabular}{lcccccccc}
\hline \multirow{2}{*}{ CNT } & GGA & 0.14 & 0.23 & 0.23 & 0.27 & 0.11 & 0.09 & 0.18 \\
& LDA & 0.47 & 0.47 & 0.64 & 0.61 & 0.36 & 0.20 & 0.46 \\
N-CNT & GGA & 0.13 & 0.15 & 0.17 & 0.15 & 0.18 & 0.10 & 0.15 \\
& LDA & 0.46 & 0.43 & 0.40 & 0.50 & 0.42 & 0.40 & 0.44 \\
B-CNT GGA & 0.15 & 0.15 & 0.20 & 0.18 & 0.16 & 0.10 & 0.16 \\
& LDA & 0.54 & 0.35 & 0.34 & 0.55 & 0.53 & 0.22 & 0.42 \\
\hline
\end{tabular}

Functional $\quad 1 \mathrm{H}_{2} \quad 2 \mathrm{H}_{2} \quad 3 \mathrm{H}_{2} \quad 4 \mathrm{H}_{2} \quad 5 \mathrm{H}_{2} \quad 6 \mathrm{H}_{2}$ average $\mathrm{E}_{\mathrm{b}}$

\begin{tabular}{lcccccccc}
\hline \multirow{2}{*}{ CNT } & GGA & 0.14 & 0.23 & 0.23 & 0.27 & 0.11 & 0.09 & 0.18 \\
& LDA & 0.47 & 0.47 & 0.64 & 0.61 & 0.36 & 0.20 & 0.46 \\
N-CNT & GGA & 0.13 & 0.15 & 0.17 & 0.15 & 0.18 & 0.10 & 0.15 \\
& LDA & 0.46 & 0.43 & 0.40 & 0.50 & 0.42 & 0.40 & 0.44 \\
B-CNT GGA & 0.15 & 0.15 & 0.20 & 0.18 & 0.16 & 0.10 & 0.16 \\
& LDA & 0.54 & 0.35 & 0.34 & 0.55 & 0.53 & 0.22 & 0.42 \\
\hline \hline
\end{tabular}

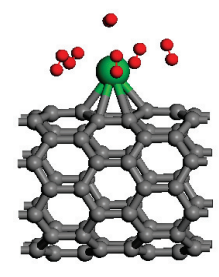

(a)

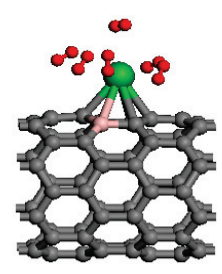

(b)

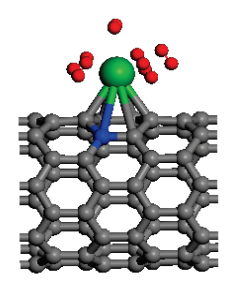

(c)
Figure. 2. (Color online) Optimized atomic geometries of Yb-decorated CNTs with maximum number of $\mathrm{H}_{2}$ molecules attached to the $\mathrm{Yb}$ atom. (a)-(c) show the geometries for maximally adsorbed $\mathrm{H}_{2}$ molecules to a $\mathrm{Yb}$ atom attached to a pristine $(8,0) \mathrm{CNT}$ and to a $(8,0) \mathrm{CNT}$ with a single a single B dopant, $\mathrm{N}$ dopant, respectively.

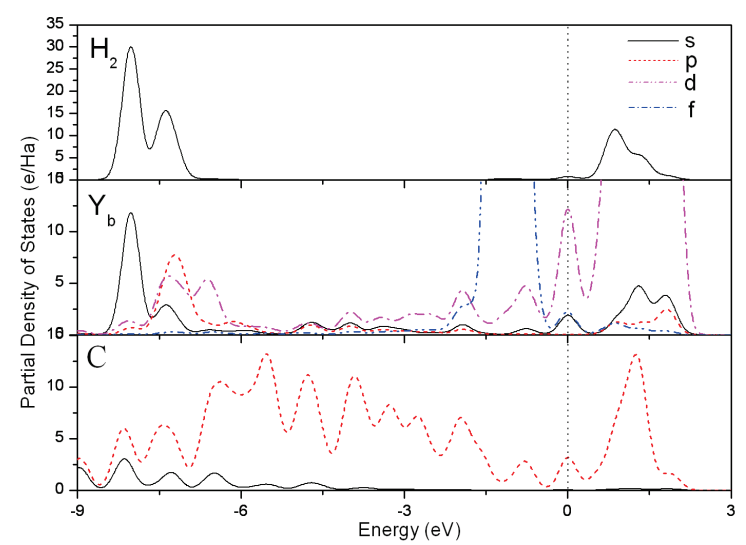

Figure 3. The partial density of states (PDOS) plots for $\mathrm{H}_{2}$ molecules, $\mathrm{Yb}$ atom and $\mathrm{C}$ atoms of the $\left(\mathrm{H}_{2}\right)_{6} / \mathrm{Yb} / \mathrm{SWCNT}$ system. The Fermi level is set to zero and indicated by a vertical dotted line

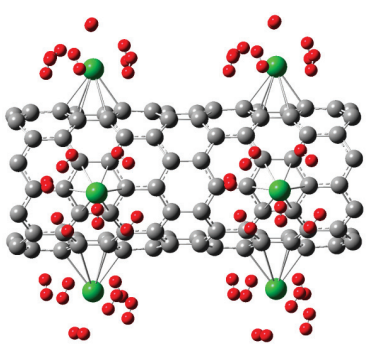

(a)

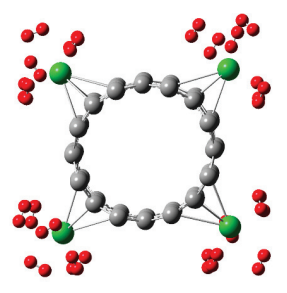

(b)
Figure. 4. (Color online) (a) and (b) show the side view and crosssectional view for the optimized atomic structure of maximal number of adsorbed $\mathrm{H}_{2}$ molecules for a $(8,0) \mathrm{CNT}(3.18 \mathrm{wt} . \%)$, respectively.

store eight $\mathrm{H}_{2}$ molecules per Eu atom, while six $\mathrm{H}_{2}$ molecules attach on the $\mathrm{Yb}$ atom, because the space of $\mathrm{RE}$ atoms outside the SWCNT is different. Pure Yb hardly attach hydrogen molecules [28, 29], however, Yb doped CNTs are capable of storing hydrogen with a mass density higher than $3.18 \mathrm{wt} \%$.

\section{Conclusion}

In conclusion, we have shown that six hydrogen molecules can be stored in the $\mathrm{Yb}$ doped CNT, B-CNT, $\mathrm{N}-\mathrm{CNT}$, respectively. The $5 \mathrm{~d}$ states of $\mathrm{Yb}$ provide an mechanism for $\mathrm{H}_{2}$ attachment as in transition-metal elements. However, unlike the transition-metal elements, $\mathrm{Yb}$ have a much lower tendency for clustering on doped CNTs and not match 18-electron rule. We also show that $\mathrm{Yb}-4 \mathrm{f}$ electrons have no contribution on the hybridization because $4 \mathrm{f}^{14}$ state is very stable. We feel that these systems can be made, and we encourage theoretic and experimental search to synthesize these RE atoms doped hydrogen storage nanomaterials.

\section{REFERENCES}

[1] National Institute for Materials Science (NIMS), President's Office, Planning Division. Materials Outlook for Energy and Environment; National Institute for Materials Science (NIMS): Japan, p 64, 2008.

[2] McAfee JL, Poirier B, J Chem Phys 130:064701, 2009.

[3] Yoon M, Yang SY, Hicke C, Wang E, Geohegan D, Zhang ZY, Phys Revs Lett 100:206806, 2008.

[4] Dillon AC, Jones KM, Bekkedahl TA, Kiang CH, Bethune DS, and Heben MJ, Nature (London) 386:377, 1997.

[5] Rosi NL, Eckert J, Eddaoudi M, Vodak DT, Kim J, Keeffe MO, Yaghi M, Science 300: 1127,2003.

[6] Kaye SS, Long JR, J Am Chem Soc 127:6506, 2005.

[7] Lee H, Ihm J, Cohen ML, Louie SG, Phys Rev B 80:115412, 2009.

[8] Ye Y, Ahn CC, Witham C, Fultz B, Liu J, Rinzler AG, Colbert D, Smith KA, Smalley RE, Appl Phys Lett 74:2307,1999. 
[9] Liu W, Zhao YH, Li Y, Jiang Q, Lavernia EG, J Phys Chem C 113:2028,2009.

[10] Chandrakumar KRS, Ghosh SK, Nano Lett 8:13, 2008.

[11] Sun Q, Jena P, Wang Q, Marguez M, J Am Chem Soc 128:9741, 2006.

[12] Kim YH, Zhao Y, Williamson A, Heben MJ, Zhang SB, Phys Rev Lett 96:016102, 2006.

[13] Park N, Hong S, Kim G, Jhi SH, J Am Chem Soc 129:8999, 2007.

[14] Dag S, Ozturk Y, Ciraci S, Yildirim T, Phys Rev Lett 94:155504,2005.

[15] Yildirim T, Ciraci S, Phys Rev Lett 94:175501, 2005.

[16] Lee H, Choi WI, Ihm J, Phys Rev Lett. 97:056104, 2007.

[17] Zhang ZW, Li JC, Jiang Q, J Phys Chem C 114:7733, 2010.

[18] Delley B, J Chem Phys 92:508, 1990.

[19] Delley B, J Chem Phys 113:7756, 2003.
[20] Wang XX, Li XY, Li HN, Phys Lett A 372:6677, 2008.

[21] Perdew JP, Burke K, Ernzerhof M, Phys Rev Lett 77:3865, 1996.

[22] Monkhorst HJ, Pack JD, Phys Rev B 13:5188, 1976.

[23] Gao Y, Zeng XC, J Phys: Condens Matter 19:386220, 2007.

[24] Cobian M, Iniguez J, J Phys: Condens Matter 20: 285212 , 2008.

[25] Henwood D, Carey JD, Phys Rev B 75:245413, 2007.

[26] Ferre-Vilaplana A, J Chem Phys 122:104709, 2005.

[27] Wu XJ, Gao, Y, Zeng XC, J Phys Chem C 112: 8458, 2008.

[28] Hirano K, Kadono J, Yamamoto S, Tanabe T, Miyake H, J Alloy Compd 408-412:351, 2006.

[29] Yoshihiro N, Kadono J, Nishiuchi S, Yamamoto S, Tanabe T, Miyake H, J Alloy Compd 408-412:355, 2006 